\title{
Regulation of CD38 Expression in Human Airway Smooth Muscle Cells
}

\section{Role of Class I Phosphatidylinositol 3 Kinases}

\author{
Joseph A. Jude ${ }^{*}$, Krishnaswamy G. Tirumurugaan ${ }^{2 *}$, Bit Na Kang1, Reynold A. Panettieri \\ Timothy F. Walseth ${ }^{4}$, and Mathur S. Kannan ${ }^{1}$ \\ ${ }^{1}$ Department of Veterinary and Biomedical Sciences, University of Minnesota, St. Paul, Minnesota; ${ }^{2}$ Department of Animal Biotechnology, Madras \\ Veterinary College, Chennai, India; ${ }^{3}$ Department of Medicine, University of Pennsylvania, Philadelphia, Pennsylvania; and ${ }^{4}$ Department of \\ Pharmacology, University of Minnesota, St. Paul, Minnesota
}

\begin{abstract}
The ADP-ribosyl cyclase activity of CD38 generates cyclic ADP-ribose, a $\mathrm{Ca}^{2+}$-mobilizing agent. In human airway smooth muscle (HASM) cells, TNF- $\alpha$ mediates CD38 expression through mitogen-activated protein kinases and NF-kB and AP-1. The phosphatidylinositol-3 kinase/Akt (PI3K/Akt) pathway is involved in TNF- $\alpha$ signaling and contributes to airway hyperresponsiveness and airway remodeling. We hypothesized that PI3Ks mediate CD38 expression and are involved in the differential induction of CD38 by TNF- $\alpha$ in asthmatic HASM cells. HASM cells were treated with pan-PI3K inhibitors (LY294002 or wortmannin) or class I-selective (GDC0941) or isoform-selective PI3K inhibitors (p110 $\alpha$-PIK-75 and p110ß-TGX221 ) with or without TNF- $\alpha$. HASM cells were transfected with a catalytically active form of $\mathrm{PI} 3 \mathrm{~K}$ or phosphatase and tensin homolog (PTEN) or nontargeting or p110 isoform-targeting siRNAs before TNF- $\alpha$ exposure. CD38 expression and activation of Akt, NF- $\kappa B$, and AP-1 were determined. LY294002 and wortmannin inhibited TNF$\alpha$-induced Akt activation, whereas only LY294002 inhibited CD38 expression. P110 expression caused Akt activation and basal and TNF- $\alpha$-induced CD38 expression, whereas PTEN expression attenuated Akt activation and CD38 expression. Expression levels of p110 isoforms $\alpha, \beta$, and $\delta$ were comparable in nonasthmatic and asthmatic HASM cells. Silencing of $p 110 \alpha$ or $-\delta$, but not $p 110 \beta$, resulted in comparable attenuation of TNF- $\alpha$-induced CD38 expression in asthmatic and nonasthmatic cells. NF-кB and AP-1 activation were unaltered by the PI3K inhibitors. In HASM cells, regulation of CD38 expression occurs by specific class I PI3K isoforms, independent of NF-KB or AP-1 activation, and PI3K signaling may not be involved in the differential elevation of CD38 in asthmatic HASM cells.
\end{abstract}

Keywords: smooth muscle; airway; CD38; PI3 kinase; PI3 kinase isoforms

CD38, an approximately $45-\mathrm{kD}$ glycosylated transmembrane protein with receptor and enzymatic functions, is expressed in a variety of mammalian cells. In airway smooth muscle (ASM) cells, ADP-ribosyl cyclase activity of CD38 generates cyclic

(Received in original form January 20, 2012 and in final form April 23, 2012)

* These authors contributed equally to this work.

Supported by National Institutes of Health grants HL057498 (M.S.K.) and HL067663, ES013508, Al068871, HL097796 (R.A.P.), a Grant-in-Aid from the University of Minnesota Graduate School (M.S.K.), and a grant from the Comparative Medicine Signature Program, College of Veterinary Medicine, University of Minnesota (M.S.K.)

Correspondence and requests for reprints should be addressed to Mathur $\mathrm{S}$ Kannan, B.V.Sc., M.Sc., Ph.D., Department of Veterinary and Biomedical Sciences, College of Veterinary Medicine, University of Minnesota, 1971 Commonwealth Avenue, St. Paul, MN 55108. E-mail: kanna001@umn.edu

Am J Respir Cell Mol Biol Vol 47, Iss. 4, pp 427-435, Oct 2012

Copyright $\odot 2012$ by the American Thoracic Society

Originally Published in Press as DOI: 10.1165/rcmb.2012-00250C on May 3, 2012

Internet address: www.atsjournals.org

\section{CLINICAL RELEVANCE}

CD38, a cell surface protein expressed in airway smooth muscle, contributes to airway hyperresponsiveness, and its expression is differentially elevated in airway smooth muscle cells from patients with asthma. The enzymatic activity of CD38 generates cyclic ADP-ribose, an important calcium mobilizing second messenger in airway smooth muscle. We report specific isoforms of class I PI3 kinase in the regulation of CD38 expression in airway smooth muscle in response to inflammatory cytokine.

ADP-ribose (cADPR), a cellular $\mathrm{Ca}^{2+}$-mobilizing agent (1, 2). In ASM cells, the intracellular calcium response elicited by contractile agonists is inhibited by antagonists of cADPR, and ASM cells obtained from CD38-deficient mice exhibit attenuated calcium responses $(3,4)$. Furthermore, airway responsiveness to inhaled methacholine is significantly lower in CD38-deficient mice compared with wild-type mice (3). Although these observations indicate that CD38/cADPR signaling has a role in ASM function, its contribution to altered ASM function in diseases such as asthma are not clear. In this context, reports from our laboratory and from others indicate a central role of CD38 in mouse models of airway inflammation and airway hyperresponsiveness (AHR), the hallmark features of asthma. For example, CD38-deficient mice develop significantly lower airway resistance to inhaled methacholine challenge after intranasal challenge with IL-13 or TNF- $\alpha$ compared with the wild-type mice, suggesting a role for this protein in the pathogenesis of AHR in airway inflammatory disorders $(5,6)$. CD38 expression and ADP-ribosyl cyclase activity are enhanced in human ASM (HASM) cells after exposure to inflammatory cytokines such as IFN- $\gamma$, IL$1 \beta$, and TNF- $\alpha$ and the $\mathrm{T}_{\mathrm{H}} 2$ cytokine IL-13 (4). Furthermore, the augmentation of CD38 expression by TNF- $\alpha$ is greater in ASM cells derived from asthmatic airways than in cells from subjects without asthma (7). Although the precise mechanisms involved in this differential induction of CD38 expression in asthmatic ASM cells are not known, transcriptional activation appears to have a major role in this process. Among the transcriptional mechanisms in the regulation of CD38 expression are mitogen-activated protein kinases (MAPKs) and transcription factors NF- $\mathrm{KB}$ and AP-1 $(8,9)$. PI3 kinase signaling is another important pathway with major roles in inflammation, AHR, and ASM cell proliferation in airway disorders such as asthma (10-12). Whether signaling mechanisms involving PI3 kinase regulate CD38 expression in HASM cells is not known.

The PI3 kinase is a member of the family of lipid kinases that phosphorylate membrane phosphatidylinositols on D3 

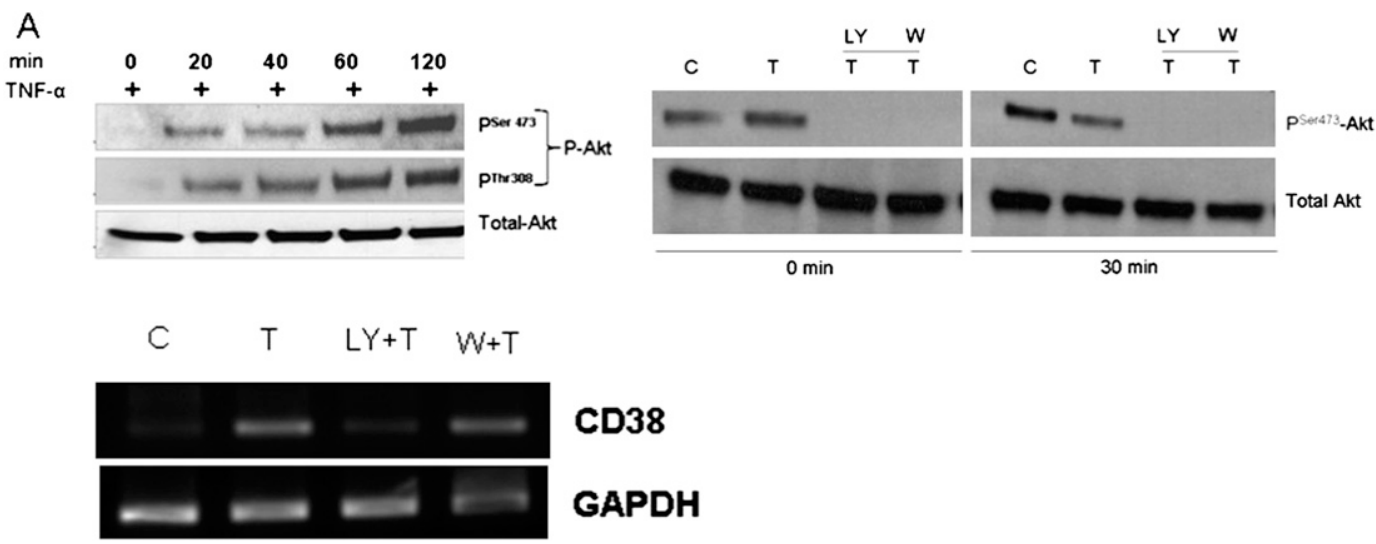

B

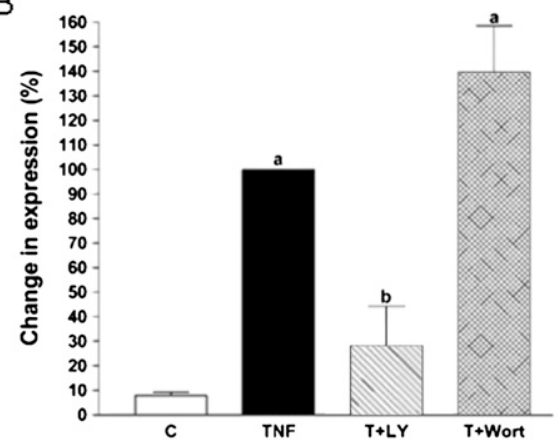

C

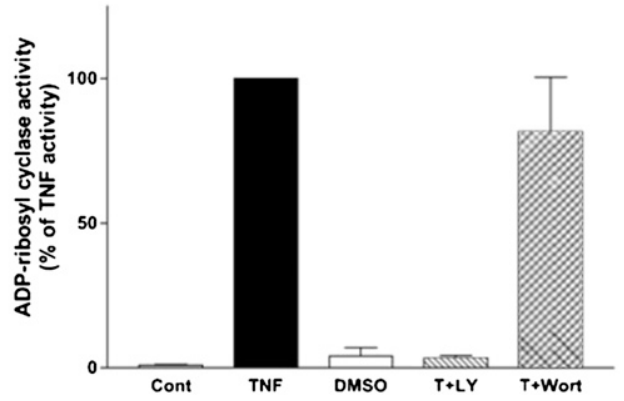

Figure 1. Effects of pan-PI3 kinase inhibitors on TNF$\alpha$-induced CD38 expression in human airway smooth muscle (HASM) cells. (A) Growtharrested HASM cells were treated with TNF- $\alpha$ for variable lengths of time (0-120 min). Note the time-dependent increase in TNF- $\alpha$-induced Akt activation (left panel). In the presence of LY294002 (3 $\mu \mathrm{M})$ or wortmannin (100 nM), there was no detectable activation of Akt in response to 0 or 30 minutes of exposure to TNF- $\alpha$ (right panel) (blot representative of four independent experiments). In the presence of LY294002 or wortmannin, exposure to TNF- $\alpha$ for 120 minutes failed to induce Akt phosphorylation (data not shown). (B) CD38 mRNA expression in the presence of PI3 kinase inhibitors. Representative agarose gel (upper panel) and quantitative RT-PCR (lower panel) show that TNF- $\alpha-$ induced CD38 mRNA expres-

sion is attenuated by LY294002 (LY+T) with no apparent inhibitory effect by wortmannin $(\mathrm{W}+\mathrm{T})$ (average of six independent experiments). (C) ADP-ribosyl cyclase activity was determined after TNF- $\alpha$ exposure (TNF) in the presence or absence of LY294002 or wortmannin. Note the inhibition of TNF- $\alpha$-induced ADP-ribosyl cyclase activity in the presence of LY294002 (T + LY), with no significant change in ADP-ribosyl cyclase activity in the presence of wortmannin ( $T+$ Wort) (average of six independent experiments). $P \leqslant 0.05 . \mathrm{a}=$ significant compared with vehicle control; $\mathrm{b}=$ significant compared with the TNF- $\alpha$ treatment).

position of the inositol ring to generate phosphatidylinositol $(3,4,5)$ trisphosphate $\left(\mathrm{PIP}_{3}\right) . \mathrm{PIP}_{3}$ induces translocation of the serine/threonine kinase Akt/PKB (protein kinase $\mathrm{B}$ ) via its pleckstrin homology domain to the cell membrane, resulting in phosphorylation by the phosphoinositides-dependent kinase 1 (PDK1). The phosphorylation of phosphatidylinositol by PI3 kinase is reversed by phosphatase and tensin homolog (PTEN), negatively regulating the PI3K/Akt signaling pathway (13). Three different classes of PI3 kinases are described based on the catalytic and regulatory isoform composition and substrate specificity (14). Among the various classes of PI3 kinases, class I PI3 kinases have been extensively studied. Based on the p110 catalytic isoforms, the class I PI3 kinase is further classified as class IA (expressing $\mathrm{p} 110 \alpha,-\beta$, and $-\delta$ ) and class IB (expressing p110 $\gamma$ ). HASM cells express class I A, class II, and class III PI3 kinases (15). The class IA PI3 kinases are generally activated by receptor and nonreceptor tyrosine kinases, whereas the other PI3 kinases are linked to various upstream signaling entities, including $G$ protein-coupled receptors (16). In studies conducted in transgenic mouse models, $\mathrm{p} 110 \delta$ and $\mathrm{p} 110 \gamma$ catalytic isoforms have been shown to play an important role in the development of AHR and airway inflammation $(11,12)$. However, these studies were focused on the role of PI3 kinase functions in the inflammatory cells of the lungs. Furthermore, the role of class I PI3 kinase signaling in the pathogenesis of asthma has been investigated in other laboratories in the context of ASM hyperplasia and airway remodeling because the PI3 kinase/Akt signaling has a critical role in cell cycle regulation and proliferation $(10,17)$.

In the present study, we hypothesized that the class I PI3 kinases have a role in TNF- $\alpha$-induced CD38 expression in HASM cells because specific isoforms within this class are involved in
AHR and CD38 contributes to AHR in mouse models of airway inflammation. The experiments were designed to investigate the role of PI3 kinases in TNF- $\alpha$-induced CD38 expression in HASM cells. We previously reported that TNF- $\alpha$-induced CD38 expression was differentially elevated in HASM cells from patients with asthma, resulting at least partially from differentially elevated ERK and p38 MAPK activation in the asthmatic cells (7). In the current study, we seek to determine whether signaling mechanisms underlying this differential induction of CD38 in asthmatic ASM cells involve class I PI3 kinases.

\section{MATERIALS AND METHODS}

\section{Human Airway Smooth Muscle Cell Culture}

HASM cells maintained in primary culture derived from airways of subjects without asthma (referred to as NAASM cells) and subjects with asthma (referred to as AASM cells) were prepared and used in their fourth or fifth passage as described in earlier publications $(4$, 18). The pan-PI3 kinase inhibitor LY294002 $(3 \mu \mathrm{M})$ or class I-selective PI3 kinase inhibitor GDC0941 $(1 \mu \mathrm{M})$ or one of the isoform-selective inhibitors (PIK75 for $\mathrm{p} 110 \alpha, 10 \mathrm{nM}$; TGX-221 for $\mathrm{p} 110 \beta, 1 \mu \mathrm{M}$ ) were added to the growth-arrested cells 30 minutes before adding TNF- $\alpha$ $(10 \mathrm{ng} / \mathrm{ml})$. The inhibitors were used in a range of concentrations ( $1 \mathrm{nM}$ to $5 \mu \mathrm{M})$, and the HASM cells were observed for signs of cytotoxicity using the 3-(4,5-dimethylthiazol-2-yl)-2,5-diphenyl tetrazolium bromide (MTT) dye reduction assay.

\section{DNA and siRNA Transfections}

Lipofectamine 2000 (DNA) or Lipofectamine RNAiMax (siRNA) (Invitrogen, Carlsbad, CA) was used according to the manufacturer's instructions. Eighteen hours after transfection, the cells were growth- 
A
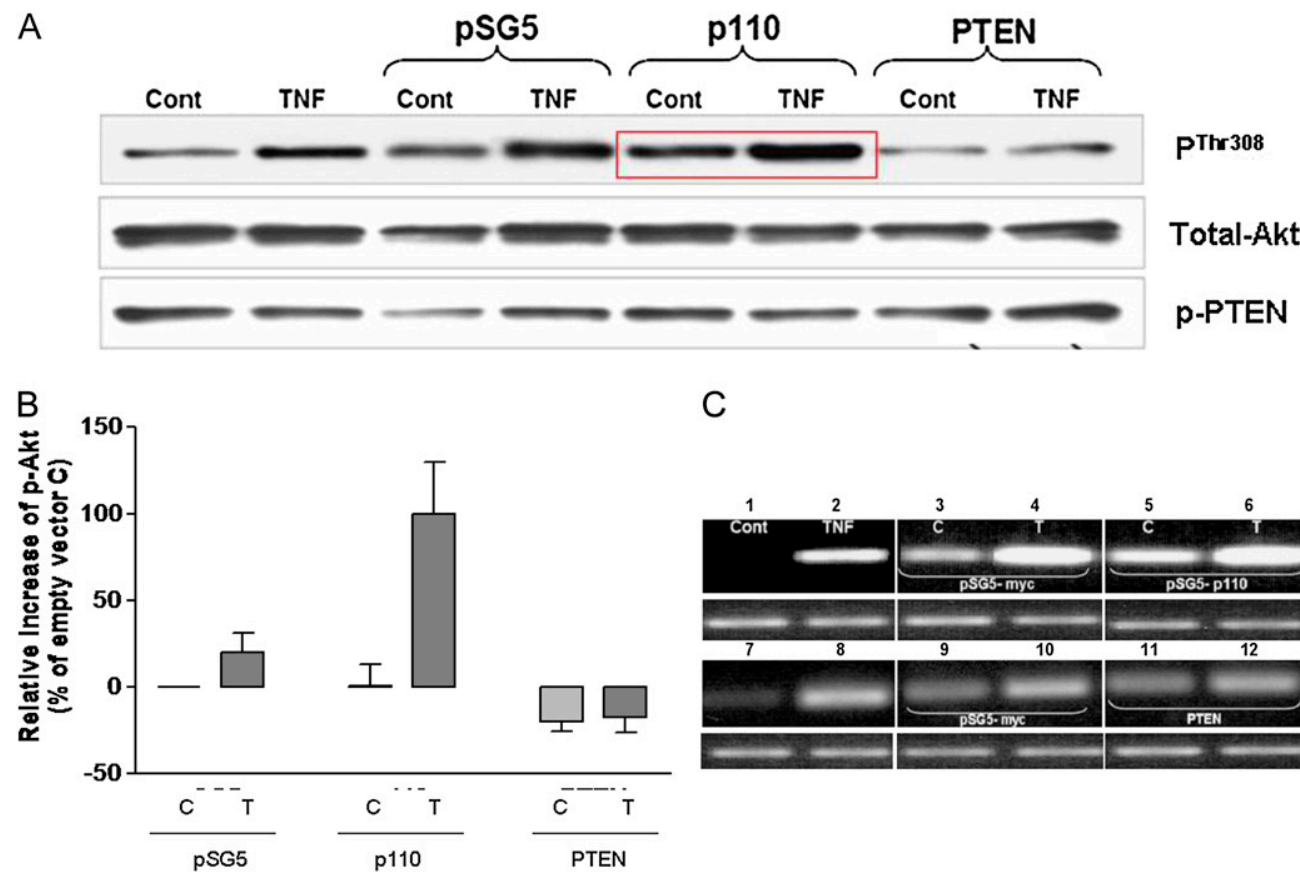

C

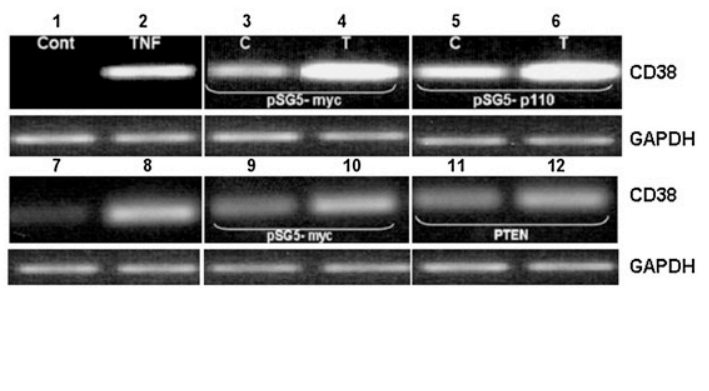

Figure 2. Effects of transient expression of $\mathrm{PI} 3$ kinase and phosphatase and tensin homolog (PTEN) on Akt activation and CD38 expression. (A) Control vector (pSG5) or vectors carrying $\mathrm{PI} 3$ kinase catalytic subunit ( $p 110)$ or PTEN construct were transfected into HASM cells and treated with TNF- $\alpha$, and the lysates were immune blotted for phosphorylated $\left(\mathrm{pThr}^{308}\right)$ and total Akt and p-PTEN. Note the elevated basal and TNF- $\alpha$-induced Akt activation in p110-transfected cells (lanes 5 and 6) compared with the control vector-transfected cells (lanes 3 and 4). PTEN transfection decreased the basal and TNF- $\alpha$-induced Akt activation (lanes 7 and 8) (blot representative of three independent experiments). (B) Bar graph shows the increase in p-Akt band intensity relative to the

vector-transfected controls (average of three independent experiments). (C) TNF- $\alpha$-induced CD38 expression in cells after transient transfection with p110 or PTEN. Representative gel image shows CD38 mRNA expression in the transfected cells. Lanes 3, 5, 9, and 11: CD38 expression in cells transfected with vector and treated with vehicle. Lanes 4, 6, 10, and 12: CD38 expression in transfected cells after exposure to TNF- $\alpha$. Note the elevated basal (lane 5) and TNF- $\alpha$-induced (lane 6) CD38 expression in p110-transfected cells. There was a lack of significant effect of PTEN transfection on basal CD38 expression (lane 11), and TNF- $\alpha$-exposure elicited only a slight increase of CD38 expression (lane 12). The image is representative of three independent experiments.

arrested for 48 hours, followed by TNF- $\alpha$ exposure for 24 hours to determine CD38 mRNA expression or 2 hours to determine Akt activation. The following were the sequences of SMART Pool siRNA oligonucleotides (Dhramacon, Lafeyette, CO) targeted against each p110 isoform (four oligonucleotides per pool): p110 $\alpha$-GUGAAAUU CUCACACUAUU, GUGGUAAAGUUCCCAGAUA, GCUUAGA GUUGGAGUUUGA, GACCCUAGCCUUAGAUAAA; $110 \beta$ GGAUUCAGUUGGAGUGAUU, GGCGGUGGAUUCACAGAUA, GAUUAUGUGUUGCAAGUCA, CCAUAGAGGCUGCCAUAAA; p1108-ACGAUGAGCUGUUCCAGUA, CCAAAGACAACAGGCA GUA, GCGUGGGCAUCAUCUUUAA, CGAGUGAAGUUUAAC GAAG.

\section{RT-PCR Reaction}

RT-PCR and qRT-PCR to determine CD38 mRNA expression were performed as described (8).

\section{ADP-Ribosyl Cyclase Assay}

A fluorescent cycling assay that measures the production of NAD from cADPR was used to quantify ADP-ribosyl cyclase activity of HASM cell lysates as described (8).

\section{ELISA for Transcription Factor Activation}

Three micrograms of nuclear extracts from HASM cells pretreated with vehicle (DMSO) or the PI3 kinase inhibitors for 30 minutes and exposed to TNF- $\alpha(10 \mathrm{ng} / \mathrm{ml}, 1 \mathrm{~h})$ was used to determine NF-кB (p65) or AP-1 (p-c-Jun) activation using Trans-AM ELISA kits (Active Motif, Carlsbad, CA) according to manufacturer's protocols.

\section{Immunoblotting}

Lysates from growth-arrested HASM cells exposed to TNF- $\alpha$ in the presence or absence of the PI3K inhibitors were resolved by SDS-PAGE, electroblotted onto polyvinylidene fluoride membrane, and incubated with the appropriate antibody (antiphospho-ERK or -ERK or -pThr ${ }^{308}$ and -pSer ${ }^{473}$ Akt or -Akt or -PTEN). The signals were amplified and visualized using antirabbit IgG and enhanced chemiluminescence (Pierce, Rockford, IL).

\section{Data Analysis}

HASM cells isolated from three to six different donors were used in the experiments. Quantitative data are shown as mean \pm SEM. Statistical analyses were performed using the GraphPad PRISM statistical software. The quantitative PCR results, ADP-ribosyl cyclase activity, and ELISA in the various samples were compared by one-way ANOVA with Bonferroni's post test for multiple comparisons. Two means were considered significantly different when $P$ value was $<0.05$.

\section{RESULTS}

\section{PI3 Kinase role in TNF- $\alpha$-Induced CD38 Expression in HASM Cells}

Growth-arrested HASM cells were treated with TNF- $\alpha$ for various lengths of time, and total cell lysates were used to determine the phosphorylated Akt $\left(\mathrm{pThr}^{308}\right.$ and $\mathrm{pSer}^{473}$ ) by Western blotting. TNF- $\alpha$ induced a time-dependent increase in the activation of Akt (Figure 1A, left panel). Pretreatment with the pan-PI3 kinase inhibitors LY294002 (3 $\mu \mathrm{M})$ or wortmannin (100 $\mathrm{nM})$ for 30 minutes abolished the TNF- $\alpha$-induced Akt activation in HASM cells (Figure 1A, right panel). In another set of experiments, cells were exposed to TNF- $\alpha(10 \mathrm{ng} / \mathrm{ml})$ for 24 hours in the presence of LY294002 or wortmannin. LY294002 inhibited TNF- $\alpha$-induced CD38 mRNA expression, whereas wortmannin had no significant effect on CD38 mRNA expression (Figure 1B). To determine the function of CD38 protein, ADP-ribosyl cyclase activity was determined in cell lysates after exposure to TNF- $\alpha(24 \mathrm{~h})$ in the presence of LY294002 or wortmannin. TNF- $\alpha$-induced ADP-ribosyl cyclase activity was 
significantly reduced in the presence of LY294002, whereas the enzyme activity was unaltered by wortmannin (Figure 1C). To further determine the role of PI3 kinase in CD38 expression, HASM cells were transiently transfected with control vector (pSG5-myc) or vectors carrying catalytically active p110 (p110) or phosphatase tensin homolog (PTEN). Transient expression of catalytically active p110 construct increased the basal and TNF$\alpha$-induced Akt activation, whereas PTEN expression reduced the basal and TNF- $\alpha$-induced Akt activation compared with the control vector-transfected cells (Figures $2 \mathrm{~A}$ and $2 \mathrm{~B}$ ). The HASM cells transiently expressing catalytically active p110 also showed elevated basal and TNF- $\alpha$-induced CD38 mRNA expression compared with the control vector-transfected cells (Figure 2C, lanes 5 and 6). Transient expression of PTEN attenuated the TNF- $\alpha$-induced CD38 mRNA expression compared with the control vector-transfected cells (Figure 2C, lanes 11 and 12).

\section{Expression of Class I PI3 Kinase Isoforms in Nonasthmatic and Asthmatic HASM Cells}

Earlier reports indicate that HASM cells express class IA p110 isoforms (i.e., p110 $\alpha, \mathrm{p} 110 \beta$, and $\mathrm{p} 110 \delta)(15,19)$. We previously reported that TNF- $\alpha$-induced CD38 expression was differentially elevated in ASM cells isolated from donors with asthma (AASM) compared with the ASM cells from donors without asthma (NAASM), although the definitive mechanisms behind the differential elevation are not known (7). To determine whether the increased induction of CD38 expression in AASM cells by TNF$\alpha$ results from differential expression of the class IA p110 isoforms, we determined their expression by Western blot. There were comparable levels of expression of $\mathrm{p} 110 \alpha,-\beta$, or $-\delta$ isoforms in NAASM and AASM cells (Figure 3A). The p110 $\gamma$ isoform was not detected in HASM cell lysates, although the same antibody detected this isoform in Jurkat cell lysates (Figure 3B).

\section{Role of Class I PI3 Kinases in TNF- $\alpha$-Induced CD38 Expression in HASM Cells}

To determine whether specific isoforms of the class I PI3 kinase are involved in TNF- $\alpha$-induced CD38 expression, pharmacological inhibitors selective for class I PI3 kinase (GDC0941) or those selective for the $\mathrm{p} 110 \alpha$ (PIK-75) or the $\mathrm{p} 110 \beta$ (TGX221 ) isoforms were used. In the presence of the class I- or isoform-selective PI3 kinase inhibitors, there was partial inhibition of TNF- $\alpha$-induced Akt activation, whereas the pan-PI3 kinase inhibitor wortmannin caused an approximately $75 \%$ reduction in Akt activation (Figures 4A and 4B). The optimal concentration of each inhibitor (i.e., the concentration with the least cytotoxicity, assessed by MTT dye reduction assay during preliminary experiments) was used in the subsequent experiments. In the presence of GDC0941 $(1 \mu \mathrm{M})$, PIK-75 $(10 \mathrm{nM})$, or TGX-221 $(1 \mu \mathrm{M})$, TNF- $\alpha$-induced CD38 mRNA expression was partially inhibited, although the reductions were not statistically significant compared with inhibition by LY294002 (Figure 4C). ADP-ribosyl cyclase activity was determined to assess the function of $\mathrm{CD} 38$ protein in the presence of the inhibitors. Although the class I-selective (GDC0941) or the p110 $\beta$-selective inhibitor (TGX-221) did not alter the TNF- $\alpha$-induced ADPribosyl cyclase activity, the p110 $\alpha$-selective inhibitor (PIK-75) caused a significant attenuation of TNF- $\alpha$-induced ADP-ribosyl cyclase activity (Figure 4D). The pan-PI3 kinase inhibitor LY294002 completely inhibited the ADP-ribosyl cyclase activity (Figure 4D). In AASM cells, the TNF- $\alpha$-induced CD38 expression was greater than that of NAASM cells, confirming our previous report (7) (Figure 4E). The magnitude of inhibition of TNF- $\alpha$-induced CD 38 mRNA expression by the class I
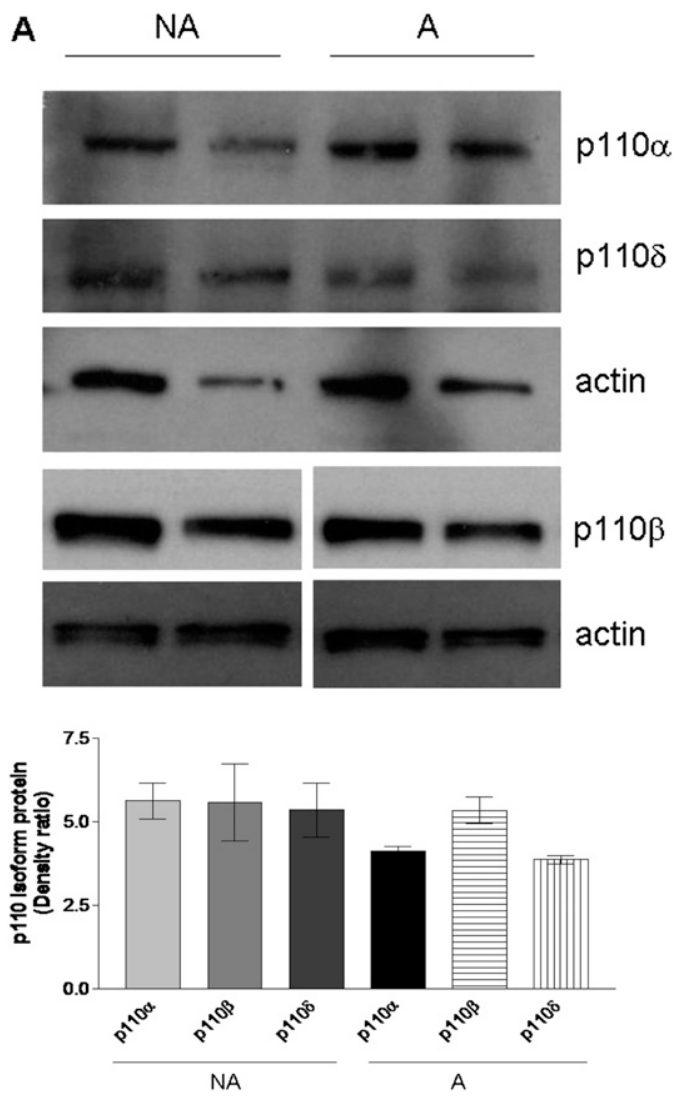

B
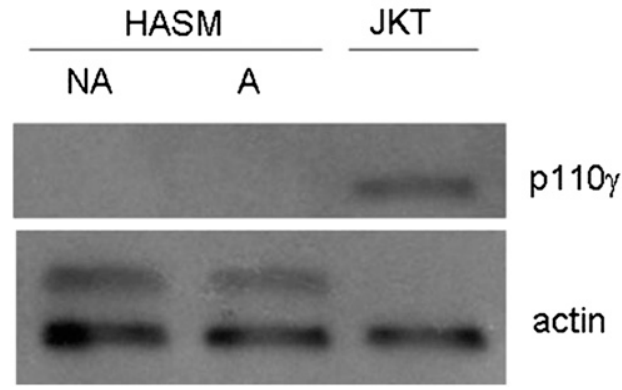

Figure 3. Expression of p110 isoforms in nonasthmatic and asthmatic HASM cells. Total cell lysates obtained from nonasthmatic and asthmatic HASM cells were immune blotted to determine expression of class IA p110 isoforms $\alpha, \beta$, and $\delta$. (A) Expression of isoforms $\alpha, \beta$, and $\delta$ were comparable in HASM cells obtained from donors with and without asthma (blots representative of four independent experiments). Densitometric analysis of the blots $(n=4)$ showing comparable expression of p110 isoforms $\alpha, \beta$, and $\delta$ between HASM cells obtained from nonasthmatic (NA) and asthmatic (A) donors. (B) The p110 isoform $\gamma$, which is categorized as the member of class IB PI3 kinases, was not detected in HASM cells. The anti-p110 $\gamma$ antibody detected the $\mathrm{p} 110 \gamma$ isoform in Jurkat cell lysate (blot representative of four independent experiments).

and the isoform-selective inhibitors was similar in NAASM and AASM cells (Figure 4E).

The cytotoxic effects of the isoform-selective PI3 kinase inhibitors limited the use of these agents to concentrations that were clearly less than optimal for significant attenuation of CD38 expression. Therefore, we chose to down-regulate the expression of the class IA p110 isoforms with siRNAs to circumvent any off-target effects of the isoform-selective chemical inhibitors. HASM cells were transfected with nontargeting, 
A

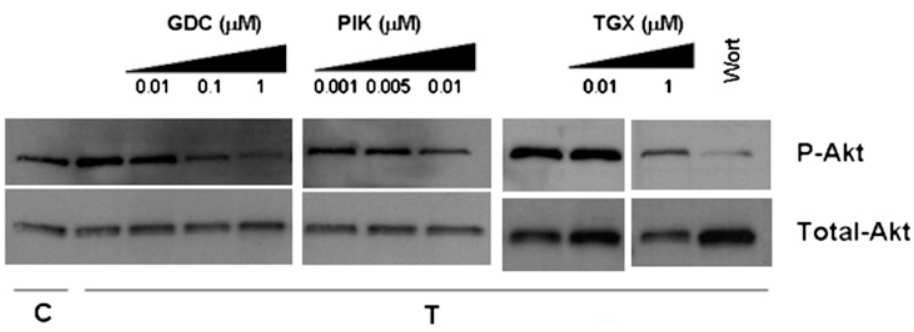

B
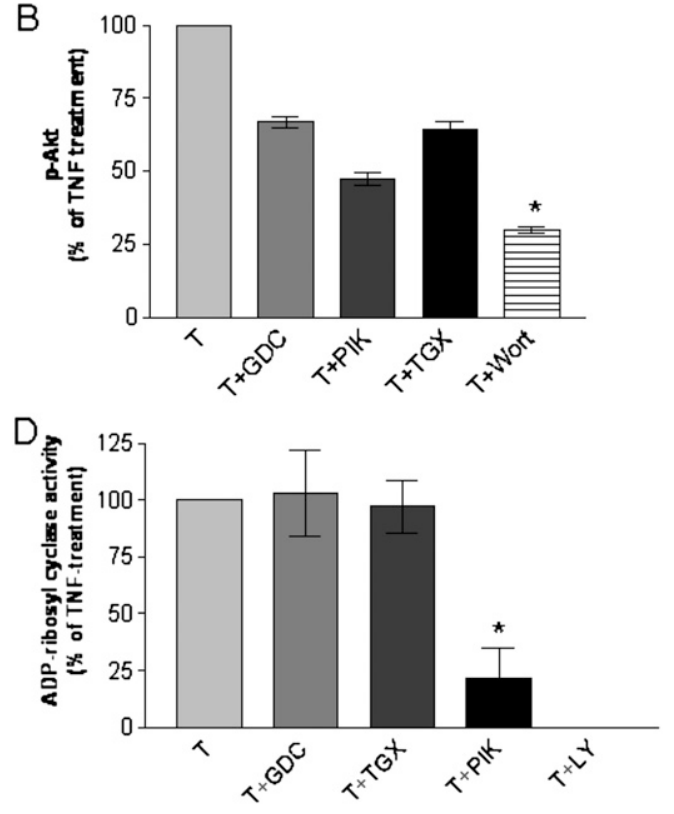

C

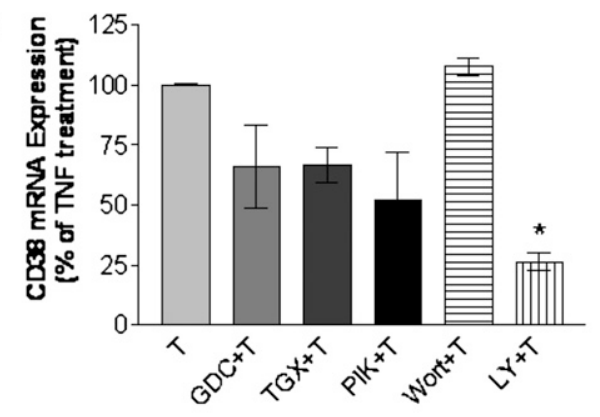

$E_{\text {. }}$

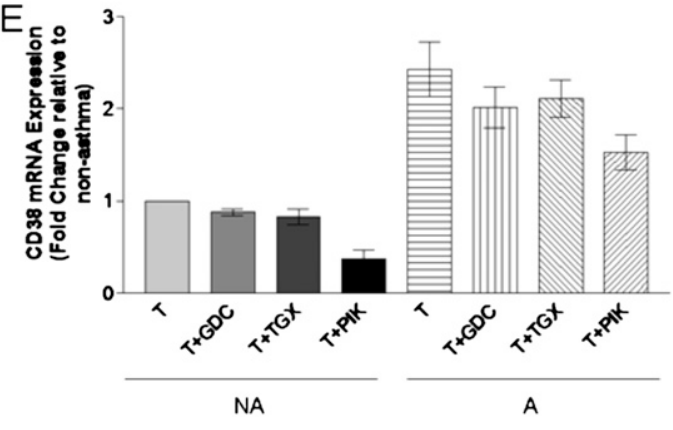

Figure 4. Effects of class I- or isoform-selective $\mathrm{PI} 3$ kinase inhibitors on TNF- $\alpha$-induced CD38 expression in HASM cells. The HASM cells were treated with vehicle or TNF- $\alpha$ in the presence of GDC0941 (class I PI3 kinase-selective inhibitor), PIK-75 (p110 $\alpha$ selective inhibitor), TGX-221 (p110 $\beta$-selective inhibitor), or the nonisoform selective PI3 kinase inhibitors LY294002 or wortmannin. (A) Representative blot showing the inhibitory effects of the PI3 kinase inhibitors on TNF- $\alpha$-induced Akt activation (blot representative of three independent experiments). (B) Densitometry ratio of $\mathrm{p}$-Akt/total Akt band intensity in cells exposed to the class $1-$ or isoform-selective $\mathrm{PI} 3$ kinase inhibitors (average of three independent experiments). Note the partial inhibition of Akt activation by the class-l- or p110 isoformselective inhibitors compared with the pan-PI3 kinase inhibitor wortmannin $\left({ }^{*} P<0.05\right.$ compared with TNF- $\alpha$ treatment). (C) TNF- $\alpha$-induced CD38 mRNA expression in cells exposed to PI3 kinase inhibitors. The class $\mathrm{I}-$ and isoform-
significance. The pan-PI3 kinase selective inhibitors partially inhibited the CD38 mRNA expression, although the reduction did not reach statistical significance. The pan-PI3 kinase inhibitor LY294002 significantly inhibited the CD38 mRNA expression (average of three independent experiments; ${ }^{*} P<0.05$ compared with TNF- $\alpha$
treatment). (D) ADP-ribosyl cyclase activity of CD38 was not altered by the class I-selective inhibitor (GDC0941) or the p110 -selective inhibitor (TGX-221). The p110 $\alpha$-selective inhibitor (PIK-75) and pan-PI3 kinase inhibitor LY294002 caused significantly decreased ADP-ribosyl cyclase activity (average of three independent experiments; ${ }^{*} P<0.05$ compared with TNF- $\alpha$ treatment). (E) TNF- $\alpha$ induced differentially elevated CD38 mRNA expression in AASM cells compared with NAASM. TNF- $\alpha$-induced CD38 expression in NAASM and AASM cells were comparably sensitive to the class I or isoform-selective PI3 kinase inhibitors (average of three independent experiments).

scrambled-sequence siRNA or siRNA targeting $\mathrm{p} 110 \alpha,-\beta$, or $-\delta$ isoforms. SiRNA silencing resulted in approximately $75 \%$ reduction in the expression of these p110 isoforms (Figures 5A and 5B). Forty-eight hours after transfection with the siRNA oligonucleotides $(10 \mathrm{nM})$, cells were treated with TNF- $\alpha$ for 24 hours, and the CD38 mRNA expression was determined. Silencing of the $\mathrm{p} 110 \alpha$ or $-\delta$ isoforms resulted in significant attenuation of TNF- $\alpha$-induced CD38 mRNA expression, whereas down-regulation of the $\mathrm{p} 110 \beta$ isoform expression did not alter TNF- $\alpha$-induced CD38 mRNA expression (Figure 5F). The effects of p110 isoform silencing on CD38 expression were also comparable between NAASM and AASM cells (Figure 5F). There was no detectable decrease in the basal or TNF- $\alpha$-induced Akt activation after siRNA-mediated silencing of the p110 isoforms in NAASM (Figures 5C and 5D) or AASM cells (Figure 5E).

\section{Role of Transcription Factors NF- $\mathrm{KB}$ and AP-1 in PI3 Kinase-Mediated CD38 Expression in HASM Cells}

To determine whether the PI3 kinase regulation of CD38 expression involves downstream activation of NF- $\mathrm{B}$ and AP-1, we used two complementary techniques. TNF- $\alpha$-induced nuclear translocation of NF-кB (p50 subunit) and AP-1 (p-c-Jun) were analyzed in the nuclear extracts of HASM cells treated with LY294002 and were found to be unaltered (Figure 6A). In an ELISA-based transcription factor activation assay, TNF$\alpha$-induced activation of NF- $\mathrm{kB}$ (Figure 6B) and AP-1 (Figure $6 \mathrm{C})$ were not significantly altered by the class $\mathrm{I}-$ or isoform selective PI3 kinase inhibitors. A model incorporating present and previous findings on the signaling mechanisms involved in the regulation of CD38 expression in HASM cells is shown in Figure 7.

\section{DISCUSSION}

In the present study, we assessed the role of the PI3 kinase/Akt pathway in TNF- $\alpha$-induced CD38 expression in HASM cells, with particular emphasis on class I PI3 kinases. We found that, apart from MAP kinases, the PI3 kinase pathway has a pivotal role in CD38 expression in HASM cells. We also investigated the contribution of the PI3 kinase signaling pathway to the differential induction of CD38 expression in asthmatic ASM cells by examining the inhibitory effects of isoform-selective inhibitors and after siRNA silencing of the p110 isoforms. Our results show that class I PI3 kinases mediate TNF- $\alpha$-induced CD38 expression in HASM cells, with 
A

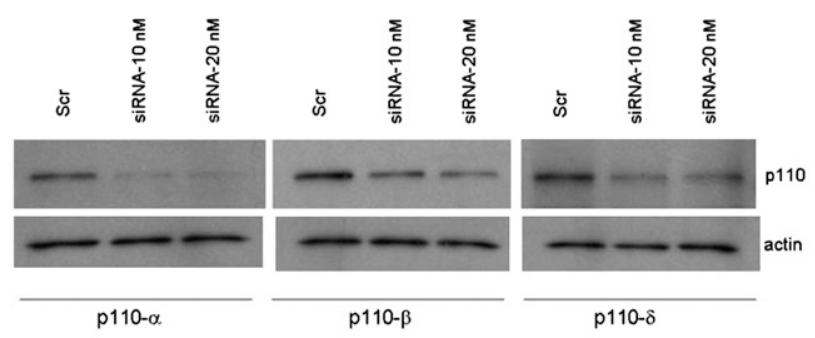

B

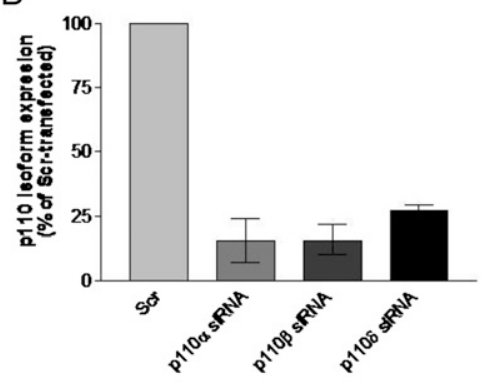

C

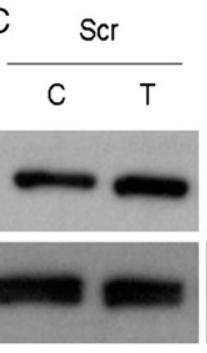

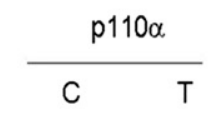
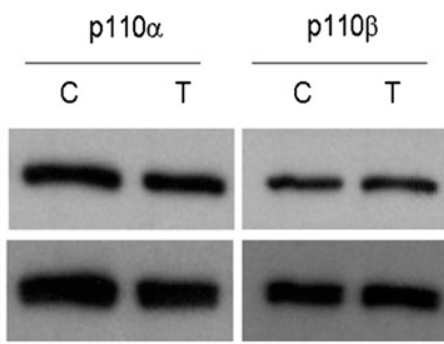

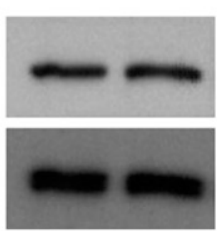

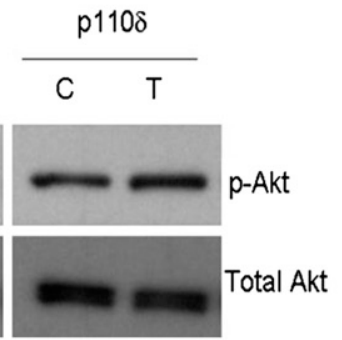
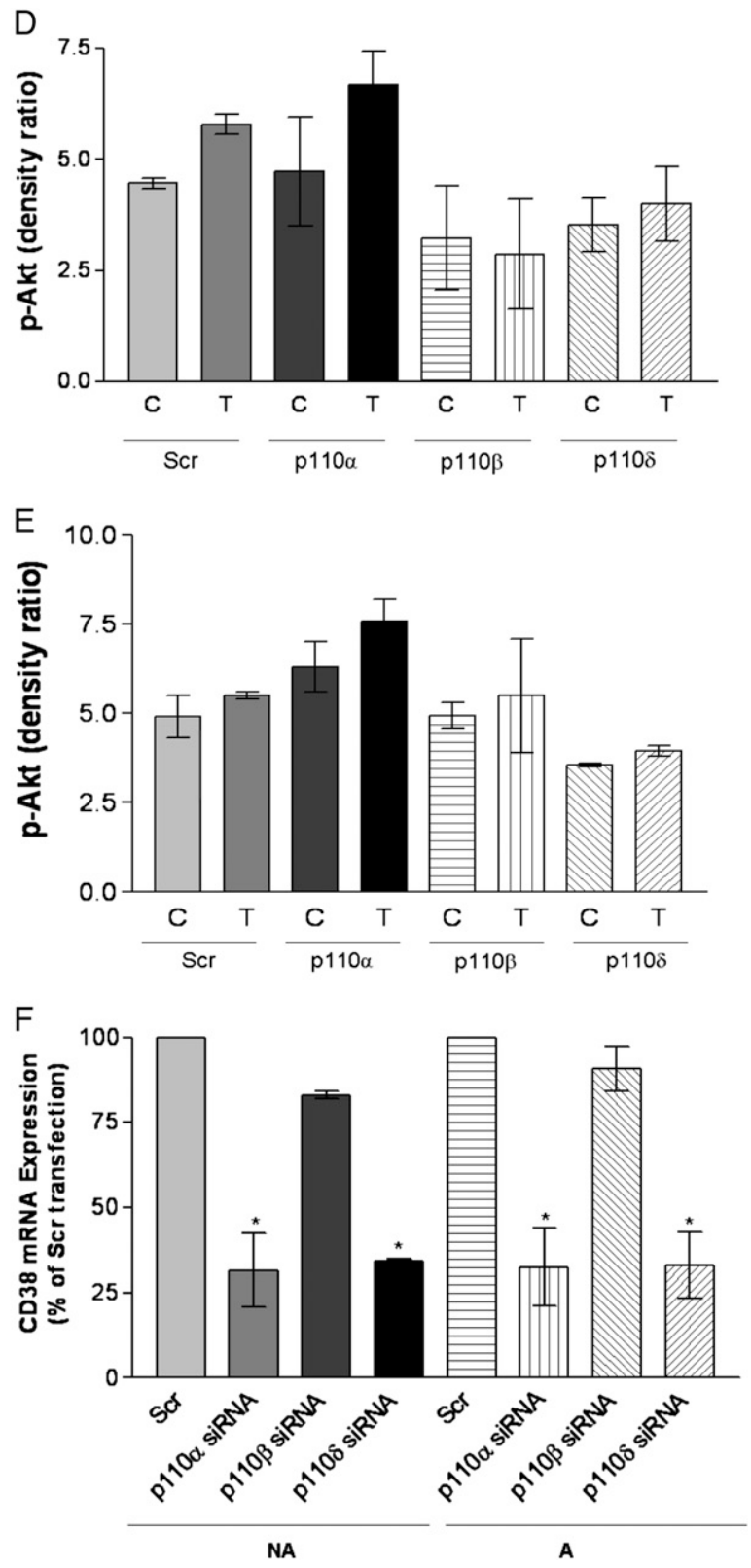

Figure 5. Effects of p110 isoform-specific siRNA on CD38 mRNA expression in HASM cells. HASM cells were transfected with siRNA targeting p110 $\alpha$, $-\beta$, and $-\delta$ isoforms and exposed to vehicle or TNF- $\alpha 72$ hours after transfection. ( $A$ ) Representative blot showing down-regulation of each p110 isoform compared with scramble siRNA-transfected cells (representative of three independent experiments). (B) Bar graph showing significant down-regulation of each p110 isoform after transfection with relevant siRNA (average of three independent experiments). (C) In HASM cells transfected with p110 isoform-targeting siRNA, there were no apparent reductions in the basal or TNF- $\alpha$-induced Akt activation (blot representative of six independent experiments; $n=3$ for each NAASM and AASM group). (D) Bar graph showing densitometric analysis of $p$-Akt levels in NAASM cells transfected with p110 isoform-targeting siRNA $(n=3)$. (E) Bar graph showing densitometric analysis of p-Akt levels in AASM cells transfected with p110 isoform-targeting siRNA $(n=3)$. (F) Silencing of p110 $\alpha$ or $-\delta$ isoform significantly attenuated TNF- $\alpha-$ induced CD38 mRNA expression, whereas silencing $\mathrm{p} 110 \beta$ did not have a significant effect on CD38 mRNA expression. The inhibitory effects of silencing p110 isoforms were comparable between NAASM and AASM cells (average of three independent experiments; ${ }^{*} P<0.05$ compared with scrambled siRNA-transfected cells)

the p110 isoforms $\alpha$ and $\delta$ playing major roles. Inhibition of the p110 $\beta$ isoform with the selective inhibitor or after siRNA silencing of its expression had no significant effect on TNF- $\alpha$-induced CD38 expression. We also found that the expression levels of class IA p110 isoforms were comparable in NAASM and AASM cells, as was the magnitude of inhibition of CD38 expression by the PI3 kinase inhibitors. PI3 kinase regulation of CD38 expression in HASM cells appears independent of activation of the transcription factors NF- $\mathrm{KB}$ or AP-1.
In a previous study, we provided evidence that regulation of CD38 expression in HASM cells involves transcriptional and posttranscriptional mechanisms (8). We further showed that the MAPK-mediated CD38 expression involves the transcription factors NF- $\mathrm{NB}$ and AP-1 as well as transcript stability. In many cell types, TNF- $\alpha$ elicits its proinflammatory effects primarily through TNF receptor 1 (TNFR1), and the induction of $C D 38$ gene is also mediated through TNFR1 $(18,20)$. The small $\mathrm{G}$ protein Ras is known to integrate the proinflammatory signals to various 
A

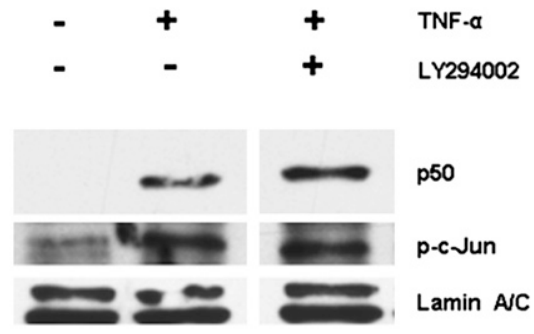

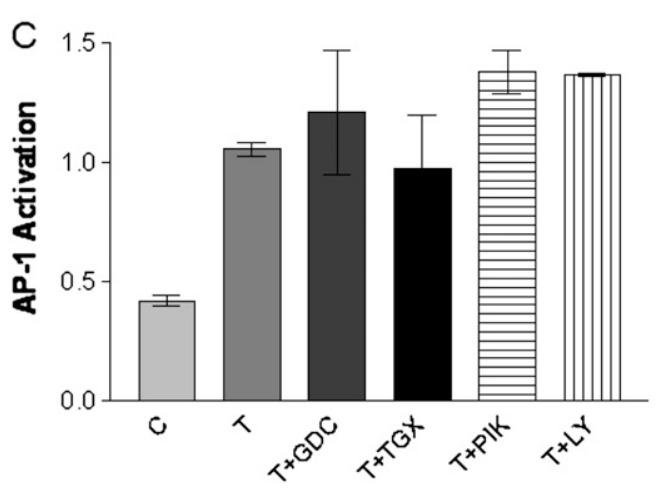

Figure 6. Effects of $\mathrm{PI} 3$ kinase inhibitors on activation of transcription factors NF- $\mathrm{KB}$ and AP-1. HASM cells were treated with vehicle or TNF- $\alpha$ for 1 hour in the presence of class I isoform-selective or pan-PI3 kinase inhibitors, and the activation of transcription factors NF- $\mathrm{kB}$ or AP-1 was determined. (A) Representative blot shows that TNF- $\alpha$-induced nuclear translocation NF-кB (p50 subunit) or AP-1 (p-c-Jun) was unaltered by the pan-PI3 kinase inhibitor LY294002. (B) TNF$\alpha$-induced NF- $\mathrm{B}$ (i.e., p65 subunit binding to consensus sequence) activation was unaltered in the presence of class Ior isoform-selective $\mathrm{PI} 3$ kinase inhibitors or pan-PI3 kinase inhibitor LY294002. (C) TNF$\alpha$-induced AP-1 (i.e., p-c-Jun subunit binding to consensus sequence) activation was unaltered in the presence of class Ior isoform-selective PI3 kinase inhibitors or pan-PI3 kinase inhibitor LY294002. signaling pathways downstream of $\operatorname{TNFR} 1(21,22)$. In mammalian cells, including ASM cells, Ras signaling involves the PI3 kinase/Akt and the MAPK pathways (23). A previous study showed that, in HASM cells isolated from donors with asthma, the PI3 kinase/Akt pathway has a major contribution to cell proliferation, compared with the ERK1/2 signaling prevalent in nonasthmatic cells (10). There is also evidence that specific p110 isoforms belonging to the class I PI3 kinases are involved in the various mechanisms that contribute to airway wall remodeling and AHR $(19,24)$. These observations prompted us to investigate the role of different p110 isoforms of class I PI3 kinases in TNF- $\alpha$-induced CD38 expression in HASM cells.

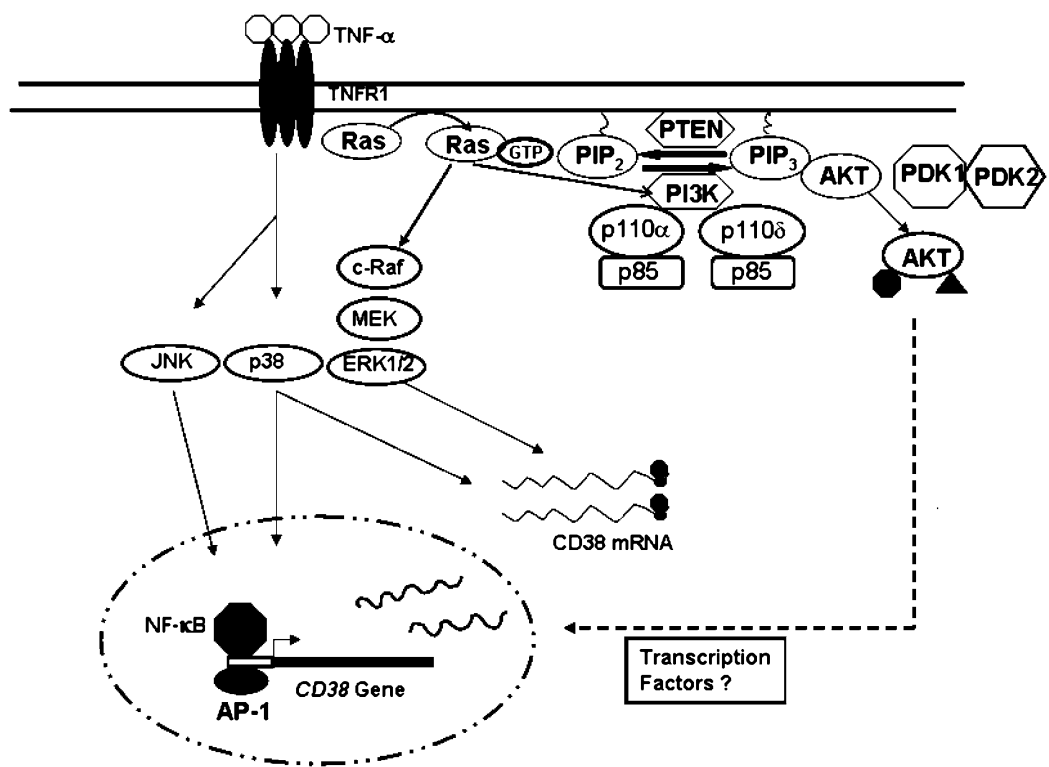

Figure 7. A proposed model for PI3 kinase regulation of CD38 expression in HASM cells. The model depicts signaling pathways known to regulate TNF- $\alpha$-induced CD38 expression in HASM cells, according to findings from our laboratory and others. Induction of CD38 and other proinflammatory genes by TNF- $\alpha$ is mediated through TNFR1 $(18,20)$. Downstream of cytokine signaling, the small Gprotein Ras is recruited and acts as an upstream regulator of PI3 kinase and MAPK signaling pathways (21-23). The PI3 kinase converts phosphatidylinositol-3,4- bisphosphate $\left(\mathrm{PIP}_{2}\right)$ into phosphatidylinositol-3,4,5-trisphosphate $\left(\mathrm{PIP}_{3}\right)$. $\mathrm{PIP}_{3}$ recruits pleckstrin homology domain-containing proteins, such as Akt and phosphoinositide-dependent kinases (PDK1 and PDK2). The Akt is phosphorylated by PDK1 and PDK2 at Thr 308 (solid circles) and Ser 473 (solid triangles), respectively. Class IA, II, and III PI3 kinases are expressed in HASM cells $(15,24)$. Our findings confirmed that $\mathrm{p} 110 \alpha$ and $-\delta$ subunits of the class IA PI3 kinases mediate TNF$\alpha$-induced CD38 expression in HASM cells. Our previous studies showed that ERK, p38, and JNK MAP kinases mediate TNF- $\alpha$-induced CD38 expression in HASM cells through transcriptional and posttranscriptional mechanisms (8). Transcriptional regulation of the $C D 38$ gene

involves activation of the transcription factors NF- $\mathrm{BB}$ and AP-1 $(8,36)$, although the PI3 kinase role in CD38 expression does not appear to be mediated through these transcription factors. The present study found that PI3 kinase does not regulate CD38 expression through modulating CD38 mRNA stability. We speculate that transcription factors other than NF- $\mathrm{KB}$ or AP-1 mediate the PI3 kinase effects in CD38 expression in HASM cells. In certain cell types, cross talk between PI3 kinase and MAPK signaling pathways has been reported at the level of c-Raf and Akt (26). However, findings from our laboratory and others did not support the existence of such a cross talk mechanism (17). 
Although the pan-PI3 kinase inhibitors Wortmannin and LY294002 were found to inhibit TNF- $\alpha$-induced Akt activation in HASM cells, significant reduction of CD38 expression was seen only in cells treated with LY294002. In previous studies in other cell systems, LY294002 has been shown to have PI3 kinase-independent effects (25). It is possible that the inhibitory effect of PI3 kinase on CD38 expression is mediated through an Akt-independent mechanism arising from off-target effects of LY294002. However, in HASM cells transiently overexpressing PTEN, TNF- $\alpha$-induced CD38 mRNA expression is reduced, as is the TNF- $\alpha$-induced Akt phosphorylation. This latter observation suggests that PI3 kinase mediates CD38 expression at least partially through Akt activation. Cross talk between the PI3 kinase and ERK MAP kinase signaling pathways has been reported in certain cell types (26). However, the findings of a previous study did not support such a mechanism in HASM cells (17). These findings, combined with our previous report on the role of MAP kinases in CD38 expression (8), suggest that MAP kinases and PI3 kinases play critical, but independent, roles in CD38 induction by TNF- $\alpha$.

Although the functions of class II and class III PI3 kinases are increasingly recognized in various systems, the class I PI3 kinase has been studied extensively using transgenic mouse models and in vitro cell systems $(15,27,28)$. In studies involving inflammatory cells, the combined role of $\mathrm{p} 110 \gamma$ and $-\delta$ isoforms in innate immune functions through T-cell development has been reported (27, 29). Among the catalytic p110 isoforms included in class I PI3 kinase, $p 110 \alpha$ and $-\beta$ are expressed ubiquitously, whereas the isoforms $\mathrm{p} 110 \delta$ and $-\gamma$ are primarily expressed in leukocytes (13). Other studies have reported that p110 isoforms $\alpha, \beta$, and $\delta$, but not $\gamma$, are expressed in HASM cells $(15,24)$. In the present study, we confirm and extend previous findings that HASM cells obtained from donors with and without asthma express p110 isoforms $\alpha, \beta$, and $\delta$ but not $\gamma$.

The salient finding of the present study is the involvement of selective p110 isoforms in TNF- $\alpha$-induced CD38 expression in HASM cells. Some of the class I p110 isoforms have been studied in the context of airway hyperresponsiveness and asthma. Inhibition of $\mathrm{p} 110 \delta$ with an isoform-selective pharmacological inhibitor significantly reduced AHR and airway inflammation in mice exposed to ovalbumin $(11,12)$. In the p110 $\delta$-mutant (inactive) mouse, allergen-induced Th2 inflammatory response was markedly attenuated, whereas the Th1-biased response was enhanced (30). Other studies using transgenic mice in which p110 or $-\gamma$ were inactivated showed that $\mathrm{p} 110 \delta$ has a predominant role in IgE-antigen complex induced hyperresponsiveness (28). In humans, studies have shown that the p110 isoform has a role in impaired glucocorticoid responsiveness in patients with COPD (31). These observations indicate that specific p110 isoforms of class I PI3 kinase can play primary roles in the pathogenesis of airway inflammatory disorders. In further support of this phenomenon, we report the predominant role of $\mathrm{p} 110 \alpha$ and $-\delta$ in the TNF- $\alpha$ induction of CD38, a molecule implicated in AHR in mouse models of allergic airway inflammation. The fact that the TNF- $\alpha$-induced CD38 expression and enzymatic activity are differentially elevated in HASM cells isolated from donors with the history of asthma lends support to the hypothesis that CD38 may be involved in human asthma (7).

The insignificant inhibitory effects on CD38 expression by class I or isoform-selective pharmacological inhibitors may be due to the evidently marginal effects on Akt phosphorylation. The maximum concentrations of the pharmacological inhibitors used in the experiments were limited by their cytotoxicity. One notable observation of the current study is that even after significant silencing of each p110 isoform by siRNA, the basal and TNF- $\alpha$-induced Akt activation remained elevated. The basal Akt activation in the different cell preparations was also variable, with some cell preparations having high levels of phosphorylated Akt and others having low to undetectable levels after growth arrest. We attribute the variable basal Akt activation to possible individual variations among donor samples. However, the observation that basal Akt activation did not result in detectable CD38 expression implies that CD38 expression may be independent of Akt activation in HASM cells. In the current study, HASM cells isolated from donors with a history of asthma were not differentially sensitive to the class I or isoform-selective inhibitors of PI3 kinase, suggesting that the functional states of the class I p110 isoforms were comparable between asthmatic and nonasthmatic HASM cells. Even in the presence of the PI3 kinase inhibitors, the magnitude of CD38 expression in AASM cells is significantly higher than in the NAASM cells exposed to TNF- $\alpha$ in the absence of any inhibitors.

In various cell types, PI3 kinase/Akt signaling regulates the expression of target genes by activating the proinflammatory transcription factor NF- $\mathrm{B}(32,33)$. A recent study described the role of PI3 kinase in the activation of the p300-NF-кB complex in cyclooxygenase-2 expression in human tracheal smooth muscle cells (34). We found no significant attenuation of $N F-\kappa B$ or AP-1 activation in the presence of the pan or isoform-selective PI3 kinase inhibitors. Furthermore, we found that the CD38 mRNA stability was not altered in the presence of pan-PI3 kinase inhibitors (data not shown), ruling out posttranscriptional regulation of CD38 expression by PI3 kinases. Therefore, transcriptional regulation appears to be the key mechanism involved in PI3 kinase regulation of CD38 expression. The role of transcription factors generally associated with PI3 kinase signaling, such as FOXO, remains to be determined in the context of CD38 expression in HASM cells (35).

In summary, our study provides new evidence that class I PI3 kinase isoforms $\alpha$ and $\delta$ regulate CD38 expression in HASM cells. This regulation does not appear to require Akt activation and may involve transcription factors other than NF- $\mathrm{B}$ and AP-1 and an increased rate of transcription involving these transcription factors. The contribution of the class I PI3 kinase isoforms to cytokine-induced CD38 expression appears similar in HASM cells from subjects with and subjects without asthma, although the inhibition of CD38 expression by isoform-selective agents is not sufficient to reverse the phenotype of the asthmatic ASM cells. The findings also suggest that more robust targeting of specific p110 isoforms to down-regulate CD38 expression may provide an attractive therapeutic target in airway inflammatory disorders like asthma.

$\underline{\text { Author disclosures }}$ are available with the text of this article at www.atsjournals.org

\section{References}

1. Lee HC, Aarhus R. ADP-ribosyl cyclase: an enzyme that cyclizes NAD + into a calcium-mobilizing metabolite. Cell Regul 1991;2:203209.

2. Howard M, Grimaldi JC, Bazan JF, Lund FE, Santos-Argumedo L, Parkhouse RM, Walseth TF, Lee HC. Formation and hydrolysis of cyclic ADP-ribose catalyzed by lymphocyte antigen CD38. Science 1993;262:1056-1059.

3. Deshpande DA, White TA, Guedes AG, Milla C, Walseth TF, Lund FE, Kannan MS. Altered airway responsiveness in CD38-deficient mice. Am J Respir Cell Mol Biol 2005;32:149-156.

4. Deshpande DA, Walseth TF, Panettieri RA, Kannan MS. CD38/cyclic ADP-ribose-mediated $\mathrm{Ca} 2+$ signaling contributes to airway smooth muscle hyper-responsiveness. FASEB J 2003;17:452-454.

5. Guedes AG, Jude JA, Paulin J, Kita H, Lund FE, Kannan MS. Role of CD38 in TNF-alpha-induced airway hyperresponsiveness. Am J Physiol Lung Cell Mol Physiol 2008;294:L290-L299.

6. Guedes AG, Paulin J, Rivero-Nava L, Kita H, Lund FE, Kannan MS CD38-deficient mice have reduced airway hyperresponsiveness following 
IL-13 challenge. Am J Physiol Lung Cell Mol Physiol 2006;291:L1286L1293.

7. Jude JA, Solway J, Panettieri RA Jr, Walseth TF, Kannan MS. Differential induction of CD38 expression by TNF-\{alpha\} in asthmatic airway smooth muscle cells. Am J Physiol Lung Cell Mol Physiol 2010;299:L879-L890.

8. Tirumurugaan KG, Jude JA, Kang BN, Panettieri RA, Walseth TF, Kannan MS. TNF-alpha induced CD38 expression in human airway smooth muscle cells: role of MAP kinases and transcription factors NF-kappaB and AP-1. Am J Physiol Lung Cell Mol Physiol 2007;292: L1385-L1395.

9. Kang BN, Tirumurugaan KG, Deshpande DA, Amrani Y, Panettieri RA, Walseth TF, Kannan MS. Transcriptional regulation of CD38 expression by tumor necrosis factor-alpha in human airway smooth muscle cells: role of NF-kappaB and sensitivity to glucocorticoids. FASEB J 2006;20:1000-1002.

10. Burgess JK, Lee JH, Ge Q, Ramsay EE, Poniris MH, Parmentier J, Roth M, Johnson PR, Hunt NH, Black JL, et al. Dual ERK and phosphatidylinositol 3-kinase pathways control airway smooth muscle proliferation: differences in asthma. J Cell Physiol 2008;216:673-679.

11. Lee KS, Park SJ, Kim SR, Min KH, Jin SM, Puri KD, Lee YC. Phosphoinositide 3-kinase-delta inhibitor reduces vascular permeability in a murine model of asthma. J Allergy Clin Immunol 2006;118:403-409.

12. Lee KS, Lee HK, Hayflick JS, Lee YC, Puri KD. Inhibition of phosphoinositide 3-kinase delta attenuates allergic airway inflammation and hyperresponsiveness in murine asthma model. FASEB $J$ 2006;20: 455-465.

13. Vanhaesebroeck B, Waterfield MD. Signaling by distinct classes of phosphoinositide 3-kinases. Exp Cell Res 1999;253:239-254.

14. Vanhaesebroeck B, Leevers SJ, Ahmadi K, Timms J, Katso R, Driscoll PC, Woscholski R, Parker PJ, Waterfield MD. Synthesis and function of 3-phosphorylated inositol lipids. Annu Rev Biochem 2001;70:535-602.

15. Krymskaya VP, Ammit AJ, Hoffman RK, Eszterhas AJ, Panettieri RA Jr. Activation of class IA PI3K stimulates DNA synthesis in human airway smooth muscle cells. Am J Physiol Lung Cell Mol Physiol 2001;280:L1009-L1018.

16. Stoyanov B, Volinia S, Hanck T, Rubio I, Loubtchenkov M, Malek D, Stoyanova S, Vanhaesebroeck B, Dhand R, Nurnberg B, et al. Cloning and characterization of a $\mathrm{G}$ protein-activated human phosphoinositide-3 kinase. Science 1995;269:690-693.

17. Krymskaya VP, Penn RB, Orsini MJ, Scott PH, Plevin RJ, Walker TR, Eszterhas AJ, Amrani Y, Chilvers ER, Panettieri RA Jr. Phosphatidylinositol 3-kinase mediates mitogen-induced human airway smooth muscle cell proliferation. Am J Physiol 1999;277:L65-L78.

18. Amrani Y, Ammit AJ, Panettieri RA Jr. Tumor necrosis factor receptor (TNFR) 1, but not TNFR2, mediates tumor necrosis factor-alphainduced interleukin-6 and RANTES in human airway smooth muscle cells: role of $\mathrm{p} 38$ and p42/44 mitogen-activated protein kinases. Mol Pharmacol 2001;60:646-655.

19. Ge Q, Moir LM, Trian T, Niimi K, Poniris M, Shepherd PR, Black JL, Oliver BG, Burgess JK. The phosphoinositide 3'-kinase p110delta modulates contractile protein production and IL-6 release in human airway smooth muscle. J Cell Physiol 2011;227:3044-3052.

20. Tliba O, Panettieri RA Jr, Tliba S, Walseth TF, Amrani Y. Tumor necrosis factor-alpha differentially regulates the expression of proinflammatory genes in human airway smooth muscle cells by activation of interferon-beta-dependent CD38 pathway. Mol Pharmacol 2004; 66:322-329.

21. Zhou L, Tan A, Iasvovskaia S, Li J, Lin A, Hershenson MB. Ras and mitogen-activated protein kinase kinase kinase-1 coregulate activator protein-1- and nuclear factor-kappaB-mediated gene expression in airway epithelial cells. Am J Respir Cell Mol Biol 2003;28:762-769.

22. Karnoub AE, Weinberg RA. Ras oncogenes: split personalities. Nat Rev Mol Cell Biol 2008;9:517-531.

23. Hershenson MB, Abe MK. Mitogen-activated signaling in airway smooth muscle: a central role for Ras. Am J Respir Cell Mol Biol 1999;21:651654.

24. Moir LM, Trian T, Ge Q, Shepherd PR, Burgess JK, Oliver BG, Black JL. Phosphatidylinositol 3-kinase isoform-specific effects in airway mesenchymal cell function. J Pharmacol Exp Ther 2011;337:557566.

25. Tolloczko B, Turkewitsch P, Al-Chalabi M, Martin JG. LY-294002 [2(4-morpholinyl)-8-phenyl-4H-1-benzopyran-4-one] affects calcium signaling in airway smooth muscle cells independently of phosphoinositide 3-kinase inhibition. J Pharmacol Exp Ther 2004;311:787-793.

26. Zimmermann S, Moelling K. Phosphorylation and regulation of Raf by Akt (protein kinase B). Science 1999;286:1741-1744.

27. Swat W, Montgrain V, Doggett TA, Douangpanya J, Puri K, Vermi W, Diacovo TG. Essential role of PI3Kdelta and PI3Kgamma in thymocyte survival. Blood 2006;107:2415-2422.

28. Ali K, Camps M, Pearce WP, Ji H, Ruckle T, Kuehn N, Pasquali C, Chabert C, Rommel C, Vanhaesebroeck B. Isoform-specific functions of phosphoinositide 3-kinases: p110 delta but not p110 gamma promotes optimal allergic responses in vivo. J Immunol 2008;180:2538-2544.

29. Webb LM, Vigorito E, Wymann MP, Hirsch E, Turner M. Cutting edge: $\mathrm{T}$ cell development requires the combined activities of the p110gamma and p110delta catalytic isoforms of phosphatidylinositol 3-kinase. J Immunol 2005;175:2783-2787.

30. Nashed BF, Zhang T, Al-Alwan M, Srinivasan G, Halayko AJ, Okkenhaug K, Vanhaesebroeck B, Hayglass KT, Marshall AJ. Role of the phosphoinositide 3-kinase p110delta in generation of type 2 cytokine responses and allergic airway inflammation. Eur J Immunol 2007;37:416-424.

31. Marwick JA, Caramori G, Casolari P, Mazzoni F, Kirkham PA, Adcock IM, Chung KF, Papi A. A role for phosphoinositol 3-kinase delta in the impairment of glucocorticoid responsiveness in patients with chronic obstructive pulmonary disease. J Allergy Clin Immunol 2010; 125:1146-1153.

32. Oviedo-Boyso J, Cortes-Vieyra R, Huante-Mendoza A, Yu HB, ValdezAlarcon JJ, Bravo-Patino A, Cajero-Juarez M, Finlay BB, BaizabalAguirre VM. The phosphoinositide-3-kinase-Akt signaling pathway is important for Staphylococcus aureus internalization by endothelial cells. Infect Immun 2011;79:4569-4577.

33. Lin $\mathrm{CH}$, Cheng HW, Ma HP, Wu CH, Hong CY, Chen BC. Thrombin induces NF-kappaB activation and IL-8/CXCL8 expression in lung epithelial cells by a Rac1-dependent PI3K/Akt pathway. J Biol Chem 2011;286:10483-10494.

34. Yang CM, Lee IT, Lin CC, Yang YL, Luo SF, Kou YR, Hsiao LD. Cigarette smoke extract induces COX-2 expression via a PKCalpha/ c-Src/EGFR, PDGFR/PI3K/Akt/NF-kappaB pathway and p300 in tracheal smooth muscle cells. Am J Physiol Lung Cell Mol Physiol 2009; 297:L892-L902.

35. Brownawell AM, Kops GJ, Macara IG, Burgering BM. Inhibition of nuclear import by protein kinase B (Akt) regulates the subcellular distribution and activity of the forkhead transcription factor AFX. Mol Cell Biol 2001;21:3534-3546.

36. Tirumurugaan KG, Kang BN, Panettieri RA, Foster DN, Walseth TF, Kannan MS. Regulation of the $\operatorname{cd} 38$ promoter in human airway smooth muscle cells by TNF-alpha and dexamethasone. Respir Res 2008;9:26. 